\title{
Knowledge of emergency contraceptives among secondary school learners in the rural area of Moletji-Mashashane, Limpopo Province, South Africa
}

\author{
P R Mamabolo, BA, DipHE, BEd (Hons), MEd \\ Research Administration and Development Office, University of Limpopo, Polokwane, South Africa
}

Corresponding author: P R Mamabolo (patrickmamas@gmail.com)

\begin{abstract}
Background. Teenagers at the reproductive age face the dilemma of choosing the best birth control method. Knowledge of emergency contraceptive pills (ECPs) associated with an intention to use other contraceptive methods has rarely been investigated. This study investigated the knowledge of emergency contraceptives among secondary school learners in the rural area of Moletji-Mashashane, Limpopo Province, South Africa.

Objective. To assess the knowledge of and barriers against emergency contraception among secondary school learners.

Methods. An anonymous questionnaire was used in the study. It included single and multiple-choice questions.

Results. A total of 469 learners aged 14 - 18 years completed the anonymous, self-administered questionnaire. The results showed that secondary school learners did not have good knowledge of emergency contraceptives; $47.5 \%$ reported that they had heard of emergency contraceptives, while 52.5\% reported that they had never heard of emergency contraceptives. The majority of learners had misperceptions about the details and safety of ECPs. However, $48.4 \%$ reported that emergency contraceptives are effective in preventing pregnancy.

Conclusion. The awareness of ECPs was not high in this group. An improved multisectoral approach to education about emergency contraceptives, with greater participation by schools and the Department of Health, is advised. A systematic and long-term intervention among secondary school learners must be conducted to educate learners about emergency contraceptives.
\end{abstract}

S Afr J Obstet Gynaecol 2017;23(3):80-84. DOI:10.7196/SAJOG.2017.v23i3.1205

Awareness of emergency contraceptive pills (ECPs) associated with an intention to use other contraceptive methods has rarely been

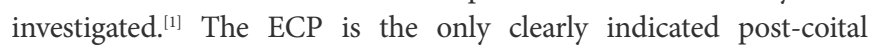
contraceptive method to prevent pregnancy in this age group. ${ }^{[2]}$ National organisations have made emergency contraception a high priority to control unintended pregnancy. The consequences of unprotected sex, such as unintended pregnancy and unsafe abortion can be prevented by access to contraceptive services. ${ }^{\left[{ }^{[3]}\right.}$ Contraceptives are freely available to women of all ages in South Africa (SA). ${ }^{[4]}$

Despite the availability of safe and effective contraceptive methods, unintended pregnancies and sexually transmitted infections (STIs) continue to be reproductive health concerns for women, ${ }^{[5]}$ most often owing to a lack of knowledge regarding the use contraceptives. Several studies have been carried out in SA regarding contraceptive knowledge and use among all age groups and found that the effective use of contraceptives was hampered by the lack of contraceptive knowledge and incorrect use of contraceptives. ${ }^{[6-8]}$

Uninformed women are subject to misunderstanding and misinformation regarding family planning and contraception. These women are at risk of unintended pregnancies, which result in high maternal mortality and morbidity rates and high teenage pregnancy rates. ${ }^{[9]}$ It is estimated that the average woman would bear 15 children over her reproductive lifetime if no contraceptive method was used. ${ }^{[10]}$

Previous studies have found barriers to contraceptive use to include the monetary and time costs of obtaining contraception, ${ }^{[11,12]}$ the social stigma of using contraceptives in an unsupportive setting, ${ }^{[13,14]}$ concerns regarding possible side-effects, and fears that reversible methods are ineffective. ${ }^{[13,15-17]}$

A 2015 study by Hae Won ${ }^{[1]}$ assessed the gender-based differences in the awareness of ECPs among unmarried Korean university students and their intention to use contraceptive methods. The study compared the ECP awareness of males and females and the intention to use four other contraceptive methods: condoms; oral contraceptive pills; withdrawal and rhythm methods. Awareness of ECP was reported by $88.2 \%$ of the participants.

In 2013, Sychareun et al. ${ }^{[19]}$ aimed to assess the knowledge of and attitudes towards ECPs in Vientiane, the capital city of Laos. The study revealed that only $22.4 \%$ of respondents had heard of ECPs and only $17.9 \%$ of them knew the correct time frame for effective use.

Myths and misinterpretations concerning contraceptives are also factors that affect the usage of ECPs. Education about contraceptive methods must be implemented in schools to ensure that learners have sound knowledge regarding contraception.

To date, little research has been performed on ECP awareness in rural areas around Polokwane, Limpopo Province, SA. We hypothesise that the more highly educated, wealthier, younger and urban women may have heard of and have used emergency contraception than teenagers from rural areas where there is often poor access to education, health and many other services. 


\section{Methods}

\section{Research design and data collection}

This study was conducted in order to recommend health education themes that should be included in the programme for educating the youth about emergency contraceptive use in the Capricorn District, Limpopo Province, SA. Self-administered questionnaires were completed by 469 learners in their classrooms at 4 different schools. The questionnaire was administered in English as this was the language of instruction at the participating schools. Questions were developed to gather information on demographics, knowledge and use of contraception, as well as the reasons for non-usage of contraception. The questionnaire took $\sim 60 \mathrm{~min}$ for the respondents to complete.

Learners were informed that the data would be used for research purposes only and would remain confidential. Some of the questions had binary answer options, while some allowed for multiple responses and a limited number of questions were open-ended. Learners were encouraged to complete the questionnaire, although they had the option to refuse participation in the study.

\section{Data analysis, validity and reliability}

The data were analysed using SPSS 11.0 (SPSS Inc., USA). The reliability and validity of the questionnaire was confirmed by conducting a pilot study. Comments received were used to enhance the questionnaire that was ultimately used to collect data.

\section{Ethical considerations}

To ensure the safety of respondents and to prevent the violation of human rights, permission to carry out the study was sought from the School Management Team. Participation was voluntary and the participants were informed that they could withdraw from the study at any time.

\section{Results and discussion}

The study investigated the knowledge of contraception among learners around Moletji-Mashashane area. This study highlights critical information related to factors that are conducive to the use of contraceptives as reported by learners from Moletji-Mashashane. The learners responded to the questions as discussed below and in Table 1.

\section{How old are you?}

Learners were aged 14 - 18 years; the majority of the learners who participated in the study were 14 years old $(25.4 \%)$, followed by the $16-(22.6 \%)$ and 17 -year olds (13.9\%).

\section{Are you male or female?}

The majority of the respondents were female (83.2\%), which reflected the more positive attitudes and willingness of the females to participate in the study compared with their male counterparts. The females also had higher levels of contraceptive knowledge. This was perhaps unsurprising because females are the primary users of most contraceptive methods. This lack of participation of the males is not insignificant. A qualitative study of young and unmarried American men suggested that improving males' contraceptive knowledge was important in promoting contraception communication among couples. ${ }^{[21]}$

\section{Have you heard of the ECP, also known as the morning-after pill?}

Overall contraceptive knowledge was low. Only $47.5 \%$ of the respondents reported having heard of the ECP, which suggested that teenagers have a moderate level of awareness of ECPs. This is inconsistent with the findings of a large study in Poland in 2015, ${ }^{[20]}$ which found that $81 \%$ of the adolescents/young adults stated that their knowledge of contraception was sufficient for them to be in charge of their own sexual lives, while $9 \%$ mentioned that they lacked such knowledge. At least $85 \%$ of the young people studied stated that they were interested in contraception. In 2016, Darteh and Doku ${ }^{[2]}$ found that $57 \%$ percent of university students in Ghana had ever heard of EC and 36\% had ever used EC - this was similar to our findings. It has been suggested previously that subjects and courses on modern contraceptive methods and family planning should be introduced in school curricula from the secondary level. ${ }^{[23]}$ ECPs seem to be filling an important niche in reducing unplanned or unwanted pregnancies. ${ }^{[24]}$ An information programme should be designed to educate people to improve the low levels of knowledge and awareness of ECPs.

\section{How long after having sex can the ECP be taken?}

Of the respondents, $34.5 \%$ knew the correct time limit of 72 hours, while the others chose either 12, 24 or 48 hours and $21.5 \%$ did not know. In a study performed in $2010,{ }^{[25]} 62 \%$ of all pupils knew the correct time limits, which suggests that the knowledge level of our respondents should be increased. ECPs may be effective beyond the accepted prescribed period.

\section{How many times can the ECP be used in a year?}

When asked how many times the ECP could be used in a year, only $24.3 \%$ of participants knew that it could be used $>3$ times. Recent research has indicated that levonorgestrel pills can be effective for up to 5 days (120 hours) post-coitus, ${ }^{[21,22]}$ which is the same time span afforded by the copper intrauterine device, while the Yuzpe regimen is effective for up to 72 hours. ${ }^{[26]}$ Myths suggesting that ECPs would negatively impact fertility if taken more often are common; however, there are no documented long-term effects of using ECPs. ${ }^{[25]}$

\section{Is the ECP $100 \%$ effective at preventing women getting pregnant?}

Of the participants, $48.4 \%$ did not know that the ECP was not $100 \%$ effective at preventing pregnancy. Only $27.8 \%$ knew that the ECP was not $100 \%$ effective at preventing pregnancy. There has been concern in recent years that the ECP, at the population level, is not as effective as it was once thought to be. ${ }^{[27]}$ The mechanism of action of the most frequently used hormonal preparations for emergency contraception, levonorgestrel and ulipristal acetate, is still not fully understood, although clinical trials indicate that they may act by inhibiting or delaying ovulation. ${ }^{[28]}$

\section{Does the ECP also protect against some STIs?}

Only $64.9 \%$ of learners knew that the ECP does not protect against STIs. A lack of knowledge about ECPs may be one of the reasons 


\begin{tabular}{|c|c|}
\hline Question & Respondents (males and females), \% \\
\hline \multicolumn{2}{|l|}{ 1. How old are you? (years) } \\
\hline 14 & 25.4 \\
\hline 15 & 20.5 \\
\hline 16 & 22.6 \\
\hline 17 & 13.9 \\
\hline 18 & 17.5 \\
\hline \multicolumn{2}{|l|}{ 2. Are you male or female? } \\
\hline Male & 16.8 \\
\hline Female & 83.2 \\
\hline \multicolumn{2}{|c|}{ 3. Have you heard of the ECP, also known as the morning-after pill? } \\
\hline Yes & 47.5 \\
\hline No & 52.5 \\
\hline \multicolumn{2}{|c|}{ 4. How long after having sex can the ECP be taken? } \\
\hline Up to 12 hours & 12.6 \\
\hline Up to 24 hours (1 day) & 26.5 \\
\hline Up to 48 hours ( 2 days) & 4.9 \\
\hline Up to 72 hours ( 3 days) & 34.5 \\
\hline Do not know & 21.5 \\
\hline \multicolumn{2}{|c|}{ 5. How many times can the ECP be used in a year? } \\
\hline 1 & 22.5 \\
\hline 2 & 14.4 \\
\hline 3 & 9.5 \\
\hline$>3$ times & 24.3 \\
\hline Do not know & 29.3 \\
\hline \multicolumn{2}{|c|}{ 6. Is the ECP $100 \%$ effective at preventing women from getting pregnant? } \\
\hline Yes & 48.4 \\
\hline No & 27.8 \\
\hline Do not know & 23.8 \\
\hline \multicolumn{2}{|c|}{ 7. Does the ECP also protect against some STIs? } \\
\hline Yes & 13.5 \\
\hline No & 64.9 \\
\hline Do not know & 21.6 \\
\hline \multicolumn{2}{|c|}{ 8. Can a 16-year-old girl get the ECP from a pharmacy? } \\
\hline Yes & 71.1 \\
\hline No & 28.9. \\
\hline \multicolumn{2}{|c|}{ 9. Can a 16-year-old girl get the ECP from a hospital? } \\
\hline Yes & 86.6 \\
\hline No & 13.4 \\
\hline \multicolumn{2}{|c|}{ 10. Can a 16 -year-old girl get the ECP from a doctor? } \\
\hline Yes & 41.3 \\
\hline No & 58.7 \\
\hline \multicolumn{2}{|c|}{ 11. Can a doctor give a girl who is under 16 years of age the ECP without telling her parents? } \\
\hline Yes & 29.7 \\
\hline No & 55.4 \\
\hline Don’t know & 14.9 \\
\hline \multicolumn{2}{|c|}{ 12. Is it common to experience dangerous side-effects of the ECP? } \\
\hline Yes & 46.9 \\
\hline No & 13.4 \\
\hline Do not know & 39.7 \\
\hline \multicolumn{2}{|c|}{ 13. Can the ECP be used if a woman is already taking the regular contraceptive pill? } \\
\hline Yes & 15.8 \\
\hline No & 39.6 \\
\hline Do not know & 44.6 \\
\hline
\end{tabular}

why they are not used more often. ${ }^{[29]}$ It is certainly plausible that the pregnancy rate might be reduced at the expense of an increased risk of contracting STIs and HIV. ${ }^{[30]}$ Any failure in contraceptive methods represents an unprotected sexual act that could potentially expose a woman to STIs as well as unintended pregnancy. 


\section{Can a 16-year-old girl get the ECP from a pharmacy?}

When asked where the ECP could be obtained by a 16-year-old girl, $71.1 \%$ stated a pharmacy, $86.6 \%$ stated a hospital and $41.3 \%$ stated a doctor. Some learners stated only one place, while some stated two and three places. Before 1998, emergency contraception was available only through a physician. ${ }^{[31]}$ Currently, ECPs are available over the counter in many countries and commercial pharmacies in these settings provide much more of this product than the public sector. ${ }^{[32]}$ In SA, ECPs, including the Yuzpe regimen and levonorgestrel, are available but can only purchased at a pharmacy on prescription from a medical doctor. ${ }^{[33]}$ Critics of the increasing availability of ECPs have expressed concerns that easier access could have a negative effect on the use of highly effective contraceptives, such as hormonal methods, an intrauterine device, or sterilisation. ${ }^{[34]}$

\section{Can a doctor give a girl who is under 16 years old the ECP without telling her parents?}

The majority $(55.4 \%)$ of the learners knew that the doctor was not obliged to inform the parents, $29.7 \%$ of the learners thought that the parents would have to be told and very few learners (14.9\%) did not know the answer. The ECP policy related to doctors' prescriptions in Korea has caused conflicts or debates since 2001 among many interested, such as religious groups, doctors, pharmacists, social activists and ECP users. ${ }^{[35]}$

\section{Is it common to have dangerous side-effects from the ECP?}

Of the respondents, $46.9 \%$ of learners thought that it was common to have dangerous side-effects from the ECP, while $39.7 \%$ did not know the answer and $13.4 \%$ did not agree that dangerous sideeffects were common. The ECP is a safe and effective method with no contraindications. ${ }^{[36]}$ The most common side-effects (reported by $\geq 10 \%$ of users) include: dizziness, headaches, nausea, abdominal pains, uterine pains, delay of menstruation, heavy menstruation, uterine bleeding, or fatigue; some less common effects (reported by $1-10 \%$ of users) included diarrhoea, vomiting and painful menstruation. ${ }^{[37]}$ Thus, if regular use of ECPs is shown to be safe, effective and acceptable in rigorous clinical research, it would help to establish the appropriate frequency of use and define the circumstances under which a woman can use the method (or a similar product) on demand. No deaths or serious complications have been causally linked to EC. ${ }^{[38]}$

\section{Can the ECP be used if a woman is already taking the regular contraceptive pill?}

There was a general lack of knowledge when learners were asked whether the ECP could be used if a woman was already taking the ordinary contraceptive pill; many learners (44.6\%) answered with 'do not know', while a few learners (15.8\%) responded with 'yes'. Based on the ECP users' awareness of other available contraceptive methods, as well as their use of other contraceptive methods and the nature of their sexual relationships, it appears unlikely that the ECP is being used as a substitute for regular contraception among the majority of users. ${ }^{[23]}$

\section{Study limitations}

The study was limited by its descriptive nature, a low male participation rate (16.8\%) and the fact that only four schools from
Moletji-Mashashane were considered. The market share of the various products of ECP may be different in other geographical locations in SA.

\section{Conclusion}

Although the market share of the various ECPs may be different by region, this study could be extended to other geographical locations in SA. The battle against unplanned pregnancies must be fought continuously on many different fronts. The lack of appropriate in-depth knowledge of EC among learners is a cause for concern and indicates that there is a need for sexual health education and guidance in schools. ECP fulfills an important and unique role as it lowers the risk of becoming pregnant after having unprotected sex and reduces unplanned or unwanted pregnancy, especially among teenagers. It is worth noting that community health workers can also play an important role by disseminating their knowledge of EC widely when learners visit clinics.

Acknowledgements. I wish to thank Ms. Noko Monene for guidance and support throughout the study.

Author contributions. Sole author.

Funding. Research Administration and Development Office, University of Limpopo.

Conflicts of interest. None.

1. Hae Won K. Sex differences in the awareness of emergency contraceptive pills associated with unmarried Korean university students' intention to use contraceptive methods: an online survey. Reproduc Health 2015;12(1):1-14. https://doi.org/10.1186/s12978-015-0076-x

2. Stewart F, Trussell J, Van Look PFA. Emergency contraception. In: Hatcher RA, Trussell J, Nelson AL, Cates W, Stewart FH, Kowal D, eds. Contraceptive Technology. 19th ed. New York: Ardent Media, 2007.

3. Tamire W, Enqueselassie F. Knowledge, attitude, and practices on emergency contraceptives among female university students in Addis Ababa, Ethiopia. Ethiop J Health Dev 2007;21(2):111-116. https://doi.org/10.4314/ejhd.v21i2.10037

4. Ramathuba DU, Khoza LB, Netshikweta ML. Knowledge, attitudes and practice of secondary school girls towards contraception in Limpopo Province. Curationis 2012;35(1):45. https://doi. org/10.4102/curationis.v35i1.45.

5. Barbour B, Salameh P. Knowledge and practices of university students in Lebanon regarding contraception. East Mediterr Health J 2009;15(2):387-399.

6. Maja TMM, Ehlers VJ. Contraceptive practices of women in northern Tshwane, Gauteng Province. Health SA Gesondheid 2004;9(4):40-51. https://doi.org/10.4102/hsag.v9i4.179

7. Ehlers VJ, Maja T, Sellers E, Gololo M. Adolescent mothers' utilisation of reproductive health services in Gauteng Province of South Africa. Curationis 2000;23(3):43-53.

8. Ziyani IS, Ehlers VJ. 'Swazi Youths' attitudes and perceptions concerning adolescent pregnancies and contraception. Health SA Gesondheid 2006;11(1):31-42. https://doi.org/10.4102/hsag.v1 li1.213 9. Kellner A, Jooste K, Jacobs W. Perceptions of clients regarding family planning service delivery in a clinic of the greater Johannesburg Metropolitan Council. Curationis 2010;33(2):13-24.

10. Bongaarts J, Potter RE. Fertility, biology, and behavior: An analysis of the proximate determinants. London: Academic Press, 1983

11. Lewis MA. Do contraceptive prices affect demand? Stud Fam Plann 1986;17(3):126-135.

12. Janowitz B, Bratt JH. What do we really know about the impact of price changes on contraceptive use? Int Fam Plan Perspect 1996;22(1):38-40. https://doi.org/10.2307/2950801

13. Bongaarts J, Bruce J. The causes of unmet need for contraception and the social content of services. Stud Fam Plann 1995;26(2):57-75.

14. Nag M. Some cultural factors affecting costs of fertility regulation. Popul Bull UN 1984;17:17-38.

15. Athavale AV, Athavale SA. Factors influencing the decision to undergo tubectomy in a rural area of Maharashtra State. Reg Health Forum 2003;7(2):42-47.

16. Rajaretnam T, Deshpande RV. Factors inhibiting the use of reversible contraceptive methods in rural South India. Stud Fam Plann 1994;25(2):111-121.

17. Chaudhury RH. Unmet Need for contraception in South Asia: Levels, trends and determinants. Asia Pac Popul J 2001;16(3):3-22.

18. Sychareun V, Hansana V, Phengsavanh A, Phongsavan K. Awareness and attitudes towards emergency contraceptive pills among young people in the entertainment places, Vientiane City, Lao PDR. BMC Womens Health 2013;13(1):1-9. https://doi.org/10.1186/1472-6874-13-14

19. Merkh RD, Whittaker PG, Baker K, Hock-Long L, Armstrong K. Young unmarried men's understanding of female hormonal contraception. Contraception 2009;79:228-235. https://doi. org/10.1016/j.contraception.2008.10.007

20. Skrzeczkowska A, Heimrath J, Surdyka J, Zalewski J. Knowledge of contraceptive methods among adolescents/young adults. Polish J Pub Health 2015;125(3):144-148. https://doi.org/10.1515/pjph2015-0042

21. Darteh E, Doku D. Knowledge and usage of emergency contraceptives among university students in Ghana. J Community Health 2016;41(1):15-21. https://doi.org/10.1007/s10900-015-0057-6.

22. Imo CK, Isiugo-Abanihe UC, Onabanjo OD. Knowledge and use of contraceptives among urban and rural women of Abia State, Nigeria. Gend Beh 2013;11(2):5556-5568.

23. Shyam T. A new wave in the quiet revolution in contraceptive use in Nepal: the rise of emergency contraception. Reprod Health 2016;13(1):49. https://doi.org/10.1186/s12978-016-0155-7

24. Parey B, Addison L, Mark JK, et al. Knowledge, attitude and practice of emergency contraceptive pills among tertiary level students in Trinidad: A cross-sectional survey. West Indian Med J 2010;59(6):650-655 


\section{RESEARCH}

25. Byamugisha JK, Mirembe FM, Faxelid E, Gemzell-Danielsson K. Knowledge, attitudes and prescribing pattern of emergency contraceptives by health care workers in Kampala, Uganda. Acta Obstet Gynecol Scand 2007;86(9):1111-1116. https://doi.org/10.1080/00016340701444871

26. Raymond EG, Trussell J, Polis CB. Population effect of increased access to emergency contraceptive pills: a systematic review. Obstet Gynecol 2007;109(1):181-188. https://doi.org/10.1097/01. AOG.0000250904.06923.4

27. Milosavljević J, Ilić K, Krajnović D. Mechanism of action, efficacy and safety of emergency hormonal contraception (levonorgestrel and ulipristal acetate) and attitudes of pharmacists. Act Fac med Naiss 2014;31(3):155-161. https://doi.org/10.2478/afmnai-2014-0019.

28. Picavet C, van der Vlugt I, Wijsen C. Intention to use emergency contraceptive pills and the role of knowledge in a Dutch national sample. Eur J Contracept Reprod Health Care 2014;19(4):250-258. https://doi.org/10.3109/13625187.2014.910595.

29. Dupont S, Webber J, Dass K, Thornton S. Emergency contraceptive pill (ECP) and sexual risk behaviour. Int J STD AIDS 2002;13(7):482-485. https://doi.org/10.1258/09564620260079644

30. Durrance CP. The effects of increased access to emergency contraception on sexually transmitted disease and abortion rates. Econ Inq 2013;51(3):1682-1695. https://doi.org/10.111 /j.1465-7295.2012.00498.

31. Westley E, Rich S, Lawton H. The unfinished agenda: Next steps to increase access to emergency York: ICEC, 2014, http://www.cecinfo.org/custom-content/uploads/2014/01/ ICEC_Next-Steps-WEB_2014.pdf (accessed 22 January 2014).
32. Kang HS. Emergency contraceptive pills: Knowledge, attitude, and intention of high school girls in Korea. Korean J Women Health Nurs 2009;15(4):336-343. https://doi.org/10.4069/kjwhn.

33. Moreau C, Trussell J, Michelot F, Bajos N. The effect of access to emergency contraceptive pills on women's use of highly effective contraceptives: Results from a French national cohort study. Am J Public Health 2009;99(3):441-442. https://doi.org/10.2105/AJPH.2007.118935.

34. Kim S. Conflicts about classifying oral contraceptives and its discourse structure. J Korean Womens Stud 2013;29(3):81-113.

35. Dixit A, Khan ME, Bhatnagar I. Mainstreaming of emergency contraception pill in India: Challenge and opportunities. Indian I Community Med 2015:40(1):49-55, https://doiorg/10.4103/09700218.149271.

36. Cleland $\mathrm{K}$, Zhu H. Goldstuck N, Cheng L, Trussell J. The efficacy of intrauterine devices for emergency contraception: A systematic review of 35 years of experience. Hum Reprod 2012;27(7):1994-2000. https://doi.org/10.1093/humrep/des140.

37. Trussell J, Raymond EG, Cleland K. Emergency contraception: A last chance to prevent unintended pregnancy. Contemp Readings L Soc Just 2014;6(2):7-38.

Accepted 5 December 2017. 